\title{
Caracterização ambiental do rio Cotunguba, Feira Nova-PE, a partir da análise dos metais traços nos sedimentos de fundo
}

Em decorrência do lançamento de efluentes não tratados de acordo com a legislação vigente, assim como o carreamento através das chuvas dos pesticidas e defensivos agrícolas utilizados nas fazendas e áreas agriculturáveis, objetiva-se analisar a qualidade dos sedimentos e o nível de toxidade com metais traços existentes no Rio Cotunguba, Feira Nova - PE, uma vez que, junto com o Rio Capibaribe, é o maior alimentador de águas da Barragem do município de Carpina, fonte de abastecimento para aproximadamente 250 mil habitantes. A análise das amostras desses sedimentos se deu através de coletas em 4 pontos estrategicamente posicionados, tratados, previamente, no departamento de Análise Ambiental da Universidade de Pernambuco e enviados para Laboratório de Análise de Sedimentos da Universidade de Ontário - Canadá, para catalogação dos minerais bem como para detectação dos metais traços com potencial para poluição, utilizando-se dos métodos FUS-ICP (Plasma Acoplado por Indução de Fusão), o TD-ICP (Plasma Acoplado Indutivamente por Digestão Total) e INAA (Análise de Ativação Neutrônica Instrumental), adotados nos parâmetros do CONAMA, USEPA e EC. Em todos os pontos de coletas, observou-se que o nível de contaminação dos sedimentos, para alguns elementos, já apresentam índices acima do recomendado, em especial, o mercúrio e chumbo, ensejando ações de mitigação, enquanto que, em outros, o nível de toxicidade comporta-se dentro do parametrizado pelos órgãos de controle ambiental, tanto do Brasil como do mundo. A consolidação dos resultados indica que apesar de um dos metais $(\mathrm{Hg})$ estar acima dos parâmetros recomendados, a maioria deles se encontram abaixo ou dentro da margem de aceitabilidade para esse tipo de contaminação segundo os principais órgãos de controle.

Palavras-chave: Geoquímica ambiental; Sedimentos; Poluição hídrica; Metais traços.

\section{Environmental characterization of Rio Cotunguba, Feira Nova-PE, from the analysis of trace metals in the background sediments}

As a result of the discharge of untreated effluents in accordance with the current legislation, as well as the transport through the rains of the pesticides and agricultural defenses used in the farms and agricultural areas, the objective is to analyze the quality of the sediments and the level of toxicity with heavy metals existing in the Cotunguba River, Feira Nova - PE, since along with the Capibaribe River is the largest water feeder of the Carpina Dam, source of supply for approximately 300 thousand inhabitants. The analysis of the samples of these sediments was done through collections at strategically positioned points, previously treated in the Department of Environmental Analysis of the University of Pernambuco and sent to ACTLABS (Laboratory of Sediment Analysis of the University of Ontario - Canada) for cataloging the minerals, as well as for detection of heavy metals with potential for pollution, using the FUS-ICP (Fusion Induced Coupled Plasma), TD-ICP (Induced Coupled Plasma by Total Digestion) and INAA (Instrumental Neutronic Activation Analysis), adopted in the parameters of CONAMA, USEPA and EC. At all points of collection, it was observed that the level of contamination of sediments for some elements already has indices above recommended, especially mercury and lead, leading to mitigation actions, while in others the level of toxicity behaves within the parameterized by the environmental control agencies, both in Brazil and in the world. The consolidation of the results indicates that although one of the metals ( $\mathrm{Hg}$ ) is above the recommended parameters, most of them are below or within the acceptable range for this type of contamination according to the main control agencies.

Keywords: Environmental geochemistry; Sediments; Pollution; Heavy metals.

Topic: Sistemas de Gestão Ambiental

Reviewed anonymously in the process of blind peer.
Received: 29/04/2021

Approved: 30/05/2021
Claudison Vieira Albuquerque

Instituto de Tecnologia de Pernambuco, Brasil

claudisonalbuquerque@gmail.com

João Allyson Ribeiro de Carvalho (it)

Universidade de Pernambuco, Brasil

http://lattes.cnpq.br/8096236027203954

http://orcid.org/0000-0003-4771-0491

allysondecarvalho@hotmail.com
Referencing this:

ALBUQUERQUE, C. V.; CARVALHO, J. A. R.. Caracterização ambiental do rio Cotunguba, Feira Nova-PE, a partir da análise dos metais traços nos sedimentos de fundo. Revista Ibero Americana de Ciências Ambientais, v.12, n.5, p.770-783, 2021. DOI: http://doi.org/10.6008/CBPC2179-6858.2021.005.0060 


\section{INTRODUÇÃO}

Durante o processo da formação urbana os rios foram importantes no que tange ao suprimento imediato das populações instaladas em suas margens. A intensificação da urbanização a partir do final do século XVIII promoveu um desequilíbrio nestes ambientes, resultando muitos casos em sua degradação. No município de Feira Nova, Agreste de Pernambuco, esse processo, apesar de ter ocorrido mais tardiamente (a partir da década de 80 do século $X X$ ), não se eximiu de limites de tolerância que têm afetado severamente o padrão homeostático dos sistemas ambientais em sua totalidade. Sobretudo, pondo em risco a "vida e a função" dos cursos fluviais de toda a área urbana e parte da área rural do município.

Mesmo o município sendo drenado por outros rios e riachos, este trabalho fez um recorte de análise do Rio Cotunguba, com a perspectiva de compreensão da dinâmica ambiental do referido ecossistema fluvial a partir da investigação sob a ótica da geoquímica ambiental. Esse rio é um dos principais afluentes da margem direita do Médio Capibaribe, além de ser um dos cursos que alimentam a barragem do município de Carpina, segundo maior reservatório de água em $\mathrm{m}^{3}$ do Estado de Pernambuco (aproximadamente 270 milhões), ficando atrás apenas de Jucazinho (327 milhões), localizada no município de Surubim (APAC, 2013). Essa barragem abastece algo em torno de 250 mil habitantes e sua área de abrangência envolve seis municípios, são eles: Carpina, Feira Nova, Lagoa do Carro, Lagoa de Itaenga e Limoeiro e Passira.

As construções de pequenas barragens, as quais servem como reservatório de água para o gado bovino ou para a irrigação irregular diminuem consideravelmente o fluxo de água do Rio. Esse problema se intensifica pelas frequentes construções das referidas barragens em cada área privada, reverberando, inegavelmente, no curso natural do rio, em suas taxas de fluxo e na competência fluvial. Apenas durante o período chuvoso é que essas barragens transbordam, enquanto que, no restante dos meses, servem como grilhões para a sequência natural do rio, bem como para a finalidade do mesmo.

Como consequência, praticamente, houve uma considerável extinção das matas ciliares porque os proprietários dessas localidades aproveitavam os troncos das árvores para fazer cercas para a criação de gado ou para isolar suas propriedades, agravando-se ainda mais a existência do Rio. Hoje, são raras as localidades em que o rio dispõe de uma área coberta por suas matas ciliares. Outro aspecto importante a ser considerado é a retirada de sedimentos para a exploração, que ocorre por meio das mineradoras de areia e argila destinadas à construção civil. Essa atividade vem sendo crescente às margens do rio em estudo tanto na área ocupada por ele e pertencente ao município de Feira Nova, mais recentemente, como na do município de Passira. Neste último, há pelo menos duas décadas.

Considere-se também a questão do uso do rio para descartes de resíduos sólidos e efluentes domésticos e industriais, sendo os problemas relacionados, o mais recorrente na área urbana do município. A cidade apesar de ser "saneada" não trata os resíduos de forma adequada e isso corrobora para a degradação do Rio, pois ao chegar à área urbana é visível essa agressão ambiental. Durante todo o percurso urbano do rio, observam-se depósitos de água poluída, decorrente da mistura do lixo ali depositado e de esgotos instalados, impossibilitando formas de vida ou equilíbrio ambiental do rio. 
Outra questão ambiental importante é o descarte de resíduos industriais advindos das indústrias de farinha, atividade econômica expressiva no município. Considerado um dos maiores produtores do Estado, reconhecido cultural e oficialmente como "Terra da Farinha", conforme Decreto Estadual de dezembro de 2013, no 1730/13 (PERNAMBUCO, 2013). Outras indústrias instaladas na região também contribuem para o descarte de resíduos no leito do rio. Sendo esse o principal objeto de estudo deste trabalho, cujo objetivo é analisar a presença de contaminantes que se sedimentaram no leito do rio, podendo contribuir para acentuar o grau de poluição das águas do Rio Cotunguba.

\section{REVISÃO TEÓRICA}

\section{O Lançamento Indevido de Efluentes nos Rios}

O advento da industrialização datado do fim do século 18 , somado ao processo de urbanização, agravados pela intensificação do êxodo rural, o crescimento contínuo das cidades e a procura por empregos e serviços, marcaram uma nova fase na forma como o homem passou a se relacionar com o meio ambiente e com os recursos por ele ofertados (SANTOS, 2006). Pelo fato destes grandes centros em sua maioria se localizarem às margens de importantes rios e como se deu o uso e a ocupação desses espaços, a sua estrutura original foi gradativamente sendo comprometida (SOUZA, 2000).

Um dos maiores problemas enfrentados por esses rios são os lançamentos indevidos de efluentes em suas águas (SOUZA, 2000). Importante atentar que não se trata do não lançamento desses efluentes, pois, diante de tantas demandas e do crescimento vertiginoso da população mundial no último século, seria praticamente impossível não usar desse instrumento. Mas, o que se questiona é como esses efluentes estão sendo lançados e onde estão sendo lançados, se atendem o que determina a Resolução 430/2011 do CONAMA (BRASIL, 2011), cujo teor trata sobre as condições e padrões de lançamentos de efluentes em corpos de águas receptores. Em praticamente toda a resolução se busca parametrizar o lançamento desses efluentes, apontando inclusive os caminhos para a realização desses processos.

O CONAMA visa regulamentar esses lançamentos, parametrizando padrões de lançamentos (CONAMA, 2011), mas que na maioria das vezes não é respeitada. Talvez por perceberem a fragilidade do processo fiscalizatório, mesmo a perspectiva da impunidade. Fato é que apesar de o país ter uma das mais atuais e completas legislações ambientais do planeta, o que se identifica na prática destoa fortemente do que se constata na teoria.

Não são raros os estudos que comprovam que quase sempre esses parâmetros não são respeitados. Nas medições feitas, percebe-se um lançamento excessivamente maior do que os prédeterminados pelo CONAMA. São perceptíveis esses lançamentos, por exemplo, no que se refere aos esgotos domésticos, pois de acordo com o Instituto Brasileiro de Geografia e Estatística, praticamente 60\% de todas as cidades brasileiras estão desprovidas do saneamento básico (BRASIL, 2017).

\section{Análise de Sedimentos nos Rios.}

Para se aferir o nível de poluição ou contaminação das lâminas d'águas, costumeiramente são 
utilizados, ao menos, dois instrumentos de coleta. A primeira e mais comum, além de apresentar resultados mais rápidos, ocorre na análise da água. A segunda, com resultados mais consistentes e apurados, ocorre quando analisados os sedimentos desses corpos (ARINE, 2000).

O registro dos efluentes lançados em rios é facilmente identificado em uma análise da água desse espaço, porém, se o lançamento for pontual e esporádico e dependendo da quantidade lançada e da vazão desse corpo d'água, podem ocorrer resultados que possam divergir da real situação do que se pretende observar. Para isso, a periodicidade das análises de corpo hídrico precisa ocorrer em um intervalo bem curto entre uma amostra e outra, pois, como já dito, pode haver divergências entre os resultados, bem como, um falso resultado (ARINE, 2000).

Por outro lado, quando a análise ocorre nos sedimentos desses corpos d'águas, as possibilidades de acertos nesses exames são consideravelmente maiores. Isso ocorre devido a sua capacidade de retenção e acumulação de espécies contaminantes a partir da coluna d'água. Os sedimentos vêm sendo largamente utilizados para indicar o nível de poluição e contaminação ambiental, já que estes integram todos os processos que ocorrem no ecossistema aquático e terrestre adjacente (SOUZA, 2013).

De maneira geral, esses efluentes são transportados para os sedimentos pela lixiviação ocasionada nos continentes, principalmente, como espécies adsorvidas ou co-precipitadas como películas dos oxihidróxidos de $\mathrm{Fe} / \mathrm{Mn}$ e na matéria orgânica. Com a redução dos oxi-hidróxidos, esses elementos metálicos são depositados nos sistemas aquáticos (FORSTEN et al., 1983). As concentrações dos contaminantes nos sedimentos são muito maiores que nas águas, o que possibilita o seu uso como um bom indicador de contaminação ambiental, tanto atual, como pretérita, possibilitando ainda o conhecimento das principais fontes de poluição (JESUS et al., 2004).

Bryan et al. (1992) afirmam que as concentrações de metais em sedimentos podem, em alguns casos, exceder em cinco vezes as ordens de grandezas presentes nas águas e que a transformação em compostos organo-metálicos, dependendo do meio, pode aumentar em muito a sua toxicidade, principalmente no caso de chumbo e mercúrio. A identificação desses contaminantes nos sedimentos é um passo importante para o mapeamento das fontes poluidoras, pois se pode construir um processo de caracterização ambiental dos principais agentes poluidores (JESUS et al., 2004). As ações que possam advir em decorrência do mapeamento desses metais traços presentes nos sedimentos, podem resultar em intervenções mitigadoras importantes na recuperação do equilíbrio ambiental desses ecossistemas (VOLPATO et al., 2017).

Importante considerar ainda que, mediante os resultados apresentados nas análises desses sedimentos, em se constatando um número acima do que determina os parâmetros do CONAMA, em sua resolução 430 de 2011, tanto o poder público como o setor privado podem, através de ações educativas, mitigadores e reparativas, buscar equacionar esses problemas. Dentre os principais agentes poluidores encontrados nos sedimentos e, que geram preocupação por oferecerem riscos à saúde, os mais comuns ou recorrentes, conforme Arine (2000), Souza (2013) e Volpato (2017), são: cádmio, chumbo, arsênio, bário, mercúrio, esgotos, hidrocarbonetos, POPs, entre outros. 
A presença desses metais traços nos sedimentos desempenha também um papel testemunhal de um processo poluidor (CARVALHO, 2014). Pode-se constatar a partir de qual período a contaminação se instalou e, por conseguinte, é possível serem mapeadas as prováveis fontes dessa poluição. De posse desse mapeamento, as ações para mitigar ou eliminar essas fontes poluidoras se tornam mais fáceis e efetivas. É bem verdade que apesar do aporte da legislação ambiental brasileira, a aplicação, monitoramento e resultados, quase sempre não acompanham a sua contemporaneidade.

Os males advindos, tanto da poluição da água, bem como dos sedimentos são diversos e têm implicações diretas e complexas, sejam elas no meio ambiente físico ou envolvendo os seres humanos. Isso ocorre através da distribuição de água para a população ou no processo de irrigação da agricultura. Fato é que o consumidor final desses serviços é impactado e se torna potencial vítima dos malefícios oriundos desses processos poluentes. A OMS já relaciona uma série de efeitos colaterais na população mundial, resultante do uso e ou da exposição a esses agentes. Patologias que se estendem desde a alergia, irritações cutâneas, infecções, a doenças mais agressivas, como, por exemplo, câncer, má formação e mutações. (OMS, 2015).

\section{METODOLOGIA}

O trabalho pautou-se, inicialmente, em estudos de gabinete, com revisão bibliográfica, versando sobre temas, como, por exemplo, gestão dos recursos hídricos, dos efluentes e dos resíduos sólidos a partir da concepção de diagnóstico ambiental mediante a identificação de parâmetros geoquímicos em sedimentos no leito fluvial do Rio Cotunguba. Numa perspectiva metodológica, aplicada com o eixo qualitativo (na medida em que identifica os forçantes ambientais), tendo em Minayo (2008) seu principal referencial teórico e quantitativo (quando permite a mensuração dos níveis de concentração de toxidade de elementos poluentes em sedimentos fluviais), baseando-se no que propõem Marconi et al. (2010). De posse dos dados obtidos, foram realizados materiais cartográficos processados em softwares específicos (Q-GIS, Google Earth), baseando-se em dados do SIRGAS 2000. Estes dados possibilitaram a localização da área de estudo, bem como dos locais de coleta de sedimentos para análises laboratoriais, além da disposição territorial da bacia do Cotunguba, para melhor compreensão do espaço estudado.

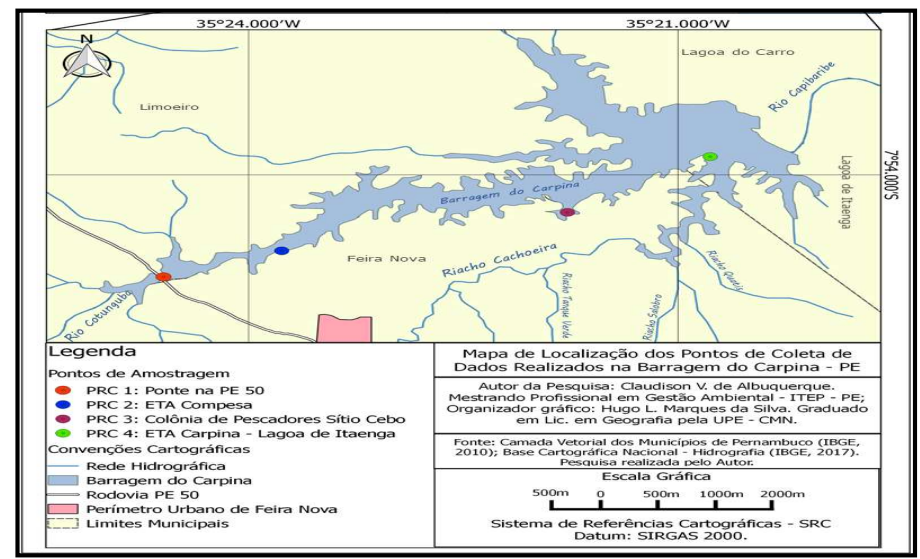

Figura 1: Mapa do Rio Cotunguba, com a marcação dos pontos de coletas. 
No segundo momento deste trabalho, coletaram-se sedimentos que foram retirados do leito do rio em quatro diferentes pontos, devidamente georreferenciados, utilizando um equipamento de GPS, modelo GARMIN, versão ETREX 10, levando em consideração a importância social, econômica e espacial dos pontos demarcados para a coleta, conforme pode ser visualizado na figura 1e tabela 1.

Tabela 1: Pontos de Coletas das Amostras de Sedimentos do Rio Cotunguba.

\begin{tabular}{lll}
\hline Ponto & Longitude oeste & Latitude sul \\
\hline PRC 01 & $35^{\circ}, 24^{\prime}$ e $36,6^{\prime \prime}$ & $70,55^{\prime}$ e $17,5^{\prime \prime}$ \\
PRC 02 & $35^{\circ}, 22^{\prime}$ e $21,1^{\prime \prime}$ & $70,54^{\prime}$ e $22^{\prime \prime}$ \\
PRC 03 & $355^{\circ}, 17^{\prime}$ e $13^{\prime \prime}$ & $70,52^{\prime}$ e 48 \\
PRC 04 & $35^{\circ}, 20^{\prime}$ e 23" & $7^{\circ}, 53^{\prime}$ e $33^{\prime \prime}$ \\
\hline
\end{tabular}

As escolhas dos pontos de visita considerou os diferentes setores estudados de modo a contemplar uma região com cerca de $10 \mathrm{~km}$ de extensão. Também foram coletadas amostras para análise laboratorial dos seguintes metais traços: $\mathrm{Cd}, \mathrm{Cr}, \mathrm{Hg}, \mathrm{Ni}, \mathrm{Pb}$ e $\mathrm{Zn}$. O material sedimentar coletado, "04 amostras", foi acondicionado em sacos plásticos, identificado com etiqueta e transportado para o Laboratório de Monitoramento Ambiental da Universidade de Pernambuco, para secagem em uma estufa de marca SLL, modelo VDO9210, por 72 horas a uma temperatura de 35․

Após a secagem, a amostra foi peneirada, sendo posteriormente desagregada, cominuída e homogeneizadas em almofariz. O material foi devidamente embalado, acondicionados em potes de polietileno, lacrados, etiquetados e enviados para o Laboratório de Análises Química da Universidade de Ontário - Canadá (ACTLABS) para análise e identificação da composição dos sedimentos, tanto de componentes naturais, bem como de elementos introduzidos pela ação antrópica, figura 02. Uma parte desse material tratado, desagregado e cominuído foi guardado em local seco e arejado para serem usados em contra prova, caso necessário.
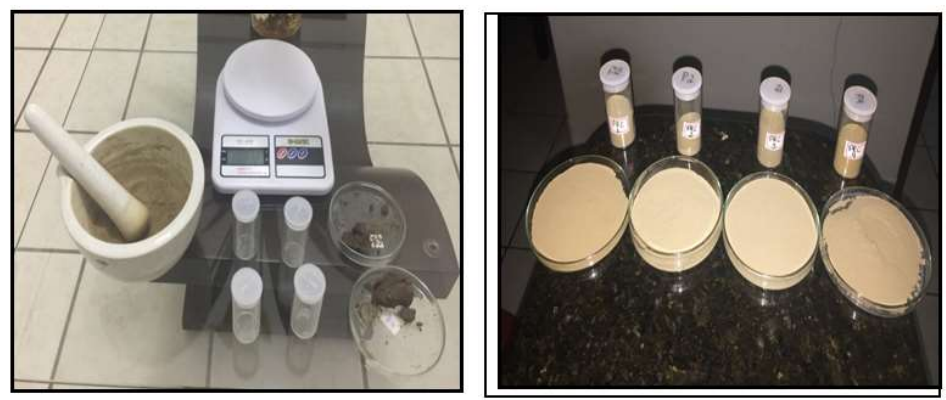

Figura 2 - Preparação dos Sedimentos em Cominuição, Embalagem e Etiquetados para análise laboratorial.

Os métodos utilizados para obtenção dos resultados foram os de FUS-ICP (Plasma Acoplado por Indução de Fusão), onde uma amostra oxidada é dissolvida em um fluxo de borato e depois diluída em ácido nítrico aquoso; o TD-ICP (Plasma Acoplado Indutivamente por Digestão Total), quando uma amostra é digerida via adição sequencial de ácidos fluorídrico, perclórico e nítrico. Os ácidos são evaporados e o resíduo é reconstituído em água régia e; INAA (Análise de Ativação Neutrônica Instrumental), cujas amostras são bombardeadas com nêutrons para gerar nuclídeos radioativos. Medição de energia e intensidade das partículas alfa geradas por decaimento subsequente é usado para quantificar os vários elementos presentes na amostra original. 

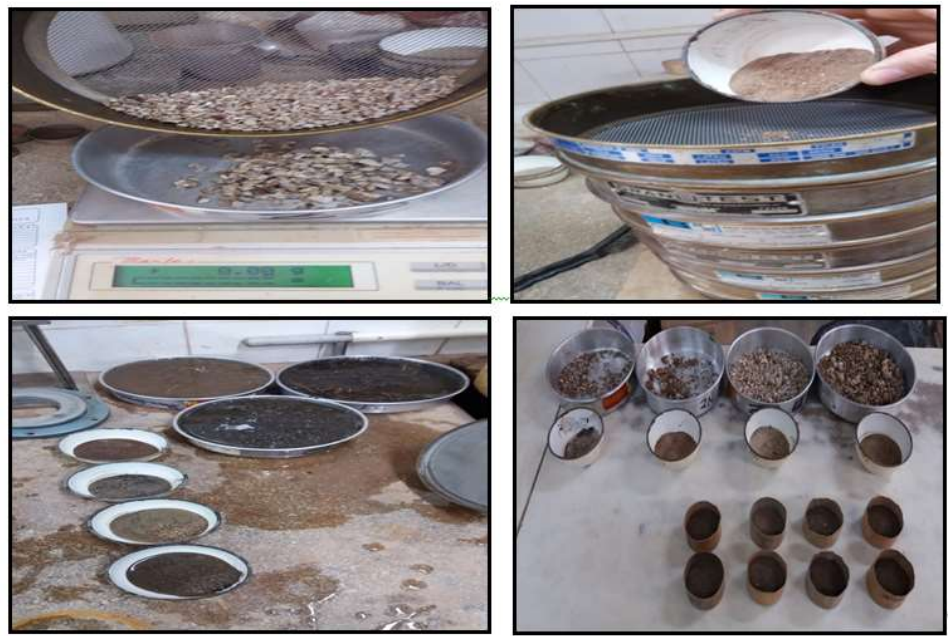

Figura 3: Mosaico de Fotos com a preparação dos sedimentos para análise granulométrica.

\section{DISCUSSÃO TEÓRICA}

\section{Análise dos Sedimentos do Rio Cotunguba Conforme Parâmetro TEL e PEL}

Após a análise por ponto de coleta, inicia-se aqui um comparativo com os parâmetros usados pelas principais agências de controle ambiental do mundo, à luz de diversos pesquisadores. Nesse tópico, foram realizadas análises de acordo com os parâmetros TEL e PEL, utilizado pela Agência Canadense de Meio Ambiente - EC.

Tabela 2 - Limites TEL (Threshold Effect Level) - PEL (Probable Effect Level) no Rio Cotunguba.

\begin{tabular}{lllllll}
\hline Elemento & $\begin{array}{l}\text { TEL } \\
\left(\mu g^{-1}\right)\end{array}$ & $\begin{array}{l}\text { PEL } \\
\left(\mu g^{-1}\right)\end{array}$ & $\begin{array}{l}\text { PRC-01 } \\
\left(\mu \mathrm{g} \mathrm{g}^{-1}\right)\end{array}$ & $\begin{array}{l}\text { PRC-02 } \\
\left(\mu \mathrm{g} \mathrm{g}^{-1}\right)\end{array}$ & $\begin{array}{l}\text { PRC-03 } \\
\left(\mu \mathrm{g} \mathrm{g}^{-1}\right)\end{array}$ & $\begin{array}{l}\text { PRC-04 } \\
\left(\mu \mathrm{g} \mathrm{g}^{-1}\right)\end{array}$ \\
\hline $\mathrm{Cd}-\mathrm{ppm}$ & 0,7 & 4,21 & $<0,5$ & $<0,5$ & $<0,5$ & $<0,5$ \\
$\mathrm{Cr}-\mathrm{ppm}$ & 52,3 & 160 & 45 & 25 & 37 & 58 \\
$\mathrm{Hg}-\mathrm{ppb}$ & 0,13 & 0,70 & 8 & $<0,5$ & 7 & 9 \\
$\mathrm{Ni}-\mathrm{ppm}$ & 15,9 & 42,8 & 18 & 7 & 7 & 12 \\
$\mathrm{~Pb}-\mathrm{ppm}$ & 30,2 & 112 & 34 & 61 & 28 & 13 \\
$\mathrm{Zn}-\mathrm{ppm}$ & 124 & 271 & 64 & 41 & 48 & 42 \\
\hline
\end{tabular}

Ao analisar a Tabela 2, os níveis de metais traços dos pontos coletados (PRC01, PRC02, PRC03 e PRC04) comparados aos parâmetros do limite TEL e PEL, padrão utilizado pela Agência Canadense de Meio Ambiente- EC, verifica-se que os elementos $\mathrm{Cd}$ e $\mathrm{Zn}$ estão com níveis de concentração que não oferecem risco ao ambiente. Em contrapartida, foram observados níveis preocupantes de $\mathrm{Cr}, \mathrm{Hg}$, $\mathrm{Ni}$ e Pb. Sobretudo o $\mathrm{Hg}$, que apresenta um nível de concentração 800\% maior em relação ao TEL.

Não diferente do Rio Cotunguba, os mesmos problemas com poluição dos sedimentos por metais traços foram apontados por Pereira (2017) em relação à Bacia do Rio São Francisco, no pólo frutífero de Petrolina-PE e Juazeiro-BA, por Araújo (2014) na Bacia do Cabo, em Cabo de Santo Agostinho - PE e por Paiva (2005) no Rio Capibaribe, na área do município de Belo Jardim - PE.

No que se refere ao $\mathrm{Cr}, \mathrm{Hg}$, $\mathrm{Ni}$ e $\mathrm{Pb}$, ao menos um dos pontos de coleta já demonstra está acima do limite de tolerância, ensejando cuidados e monitoramento. Mesmo sendo em processos hidrogeoquímicos diferentes, por ter sido realizado em regiões estuarinas, esse fato também já foi relatado em outros rios do Estado, como é o caso do Rio Capibaribe, Xavier (2017), Bacia do Pina, Brayner (2009), Rio Jaboatão, Lima (2011), Rio Maracaípe, Coimbra et al. (2015) e Rio Goiana, Miranda (2016). 


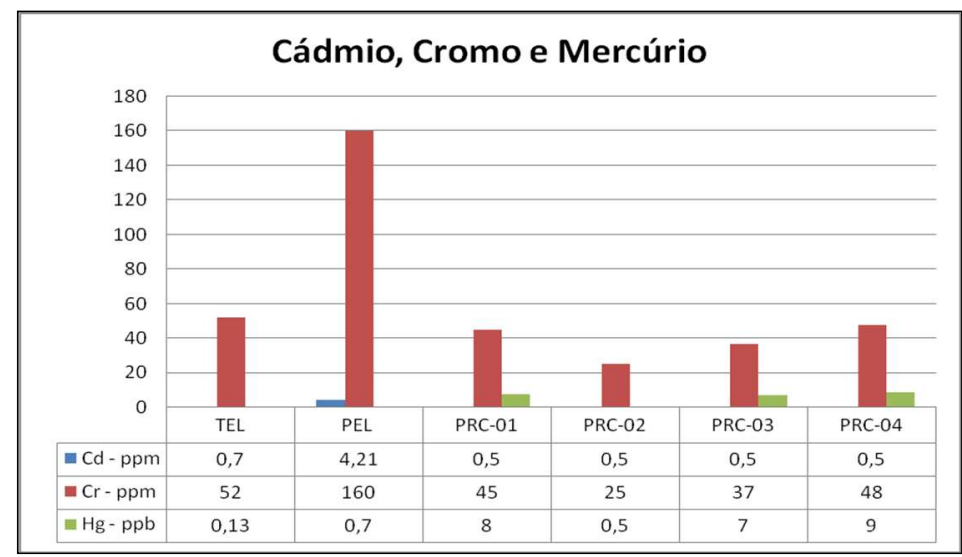

Gráfico 1: Análise Comparativa de $\mathrm{Cd}, \mathrm{Cr}$ e Hg com os parâmetros TEL e PEL.

Não foi observado nesse parâmetro variação de contaminação dos sedimentos entre os pontos coletados, indicando, portanto, que há um equilíbrio na presença de Cd. Além disso, deve se considerar também que as amostras não estão com indicativos de poluição para o metal analisado. Quanto ao $\mathrm{Cr}$, percebe-se que há uma variação considerável entre os pontos de coleta 04 e 02, algo que se aproxima de 92\% entre um ponto e o outro. Como esse metal é encontrado em adubos e fertilizantes e essas áreas são grandes concentradoras de plantação de milho para ração animal, presume-se que o uso intensivo desses fertilizantes, ao serem carreados para o leito do rio, pelas chuvas ou até mesmo pela irrigação, acumulemse e contaminem os sedimentos. Já em relação ao mercúrio, quando analisado, percentualmente, é perceptível que três dos quatros pontos de coletas não apresentem grandes variações quanto a seu nível de toxidade nos sedimentos, excetuando o ponto 02 , que demonstra está $1.700 \%$ menos contaminado que o ponto 04 , porém, apresentam números bem acima do recomendado por esse parâmetro.

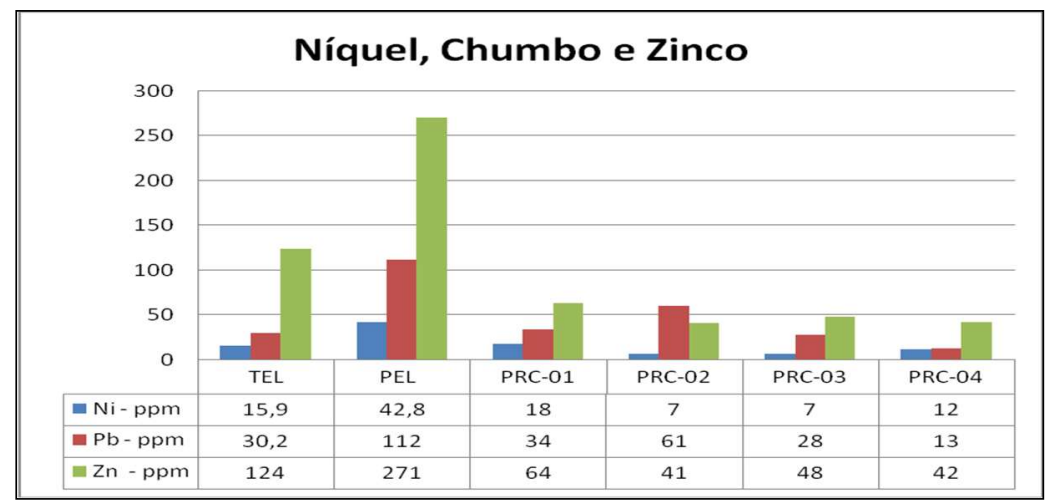

Gráfico 2: Análise Comparativa de $\mathrm{Ni}, \mathrm{Pb}$ e $\mathrm{Zn}$ com os parâmetros TEL e PEL.

No caso do Níquel, a variação entre os pontos tem dois momentos distintos. Os pontos 02 e 03 mantêm certo equilíbrio, enquanto que entre os pontos 01 e 04 há uma variação de $50 \%$ a mais da presença desse metal nas amostras coletadas, porém, é importante salientar que todas as coletas estão dentro do parâmetro determinado pela EC. Com relação ao Chumbo, o ponto 02 é o que apresenta a maior taxa de toxidade, sendo praticamente $80 \%$ maior que o ponto $01,105 \%$ maior 03 e $370 \%$ em média maior que o ponto 04 . No que se refere à presença do Zinco, as amostras 02,03 e 04 apresentam padrão próximos de toxidades, todos na casa dos 40 ppm. Apenas a amostra do 01 é que apresenta um número fora da curva em relação aos demais, aparecendo com 64 ppm, porém, todos dentro do nível de tolerância, 
determinado pelo parâmetro em estudo.

Os possíveis inputs em excesso desse metal traços nos sedimentos do Rio Cotunguba podem ser oriundos da ausência de tratamento dos efluentes domésticos e industriais lançados em todo o seu trajeto urbano, quer seja no município de Feira Nova, bem como no trecho que corta o município de Passira/Limoeiro. Apesar da ausência de grandes indústrias como fontes poluidoras, o acúmulo de lançamentos das clínicas, de consultórios hospitalares e dos esgotos domésticos tem sido suficientemente prejudiciais ao rio, como destaca Aragão (2013).

Com a ausência do tratamento e deficiência na fiscalização do poder público, ainda que as dosagens sejam de pequeno porte, a continuidade desses lançamentos tem elevado o nível de contaminação. Isso tem posto em risco a saúde de grande parte da população abastecida pela água da barragem, algo em torno de 300 mil pessoas, dos cinco municípios banhados por ela, como reitera Aragão (2013).

\section{Análise dos Sedimentos do Rio Cotunguba Conforme Parâmetro ERL e ERM}

Além dos parâmetros que subsidiam os estudos para a Agência Canadense de Clima - EC, os Estados Unidos da América, através de seu órgão de controle ambiental - USEPA, utilizam parâmetros para o controle de metais traços nos sedimentos, denominado de ERL e ERM. As análises das amostras coletadas no Rio Cotunguba, quando comparada com os parâmetros em tela são observadas nas tabelas e gráficos a seguir.

Tabela 3: Limites ERL (Effects Range-Low) - ERM (Effects Range-Medium), para sedimentos analisados do Rio Cotunguba.

\begin{tabular}{|c|c|c|c|c|c|c|}
\hline Elemento & $\begin{array}{l}\text { ERL } \\
\left(\mu \mathrm{g} \mathrm{g}^{-1}\right)\end{array}$ & $\begin{array}{l}\text { ERM } \\
\left(\mu g^{-1}\right)\end{array}$ & $\begin{array}{l}\text { PRC-01 } \\
\left(\mu g^{-1}\right)\end{array}$ & $\begin{array}{l}\text { PRC-02 } \\
\left(\mu \mathrm{g} \mathrm{g}^{-1}\right)\end{array}$ & $\begin{array}{l}\text { PRC-03 } \\
\left(\mu g^{-1}\right)\end{array}$ & $\begin{array}{l}\text { PRC-04 } \\
\left(\mu g^{-1}\right)\end{array}$ \\
\hline $\mathrm{Cd}-\mathrm{ppm}$ & 1,2 & 9,6 & $<0,5$ & $<0,5$ & $<0,5$ & $<0,5$ \\
\hline $\mathrm{Cr}-\mathrm{ppm}$ & 81,0 & 370,0 & 45 & 25 & 37 & 58 \\
\hline $\mathrm{Hg}-\mathrm{ppb}$ & 0,15 & 0,71 & 8 & $<0,5$ & 7 & 9 \\
\hline $\mathrm{Ni}-\mathrm{ppm}$ & 20,9 & 51,6 & 18 & 7 & 7 & 12 \\
\hline $\mathrm{Pb}-\mathrm{ppm}$ & 46,7 & 218,0 & 34 & 61 & 28 & 13 \\
\hline $\mathrm{Zn}-\mathrm{ppm}$ & 150 & 410,0 & 64 & 41 & 48 & 42 \\
\hline
\end{tabular}

ERL =Effects Range Low(faixa de efeitos de baixo impacto); ERM = Effects Range Medium(faixa de efeitos de médio impacto).

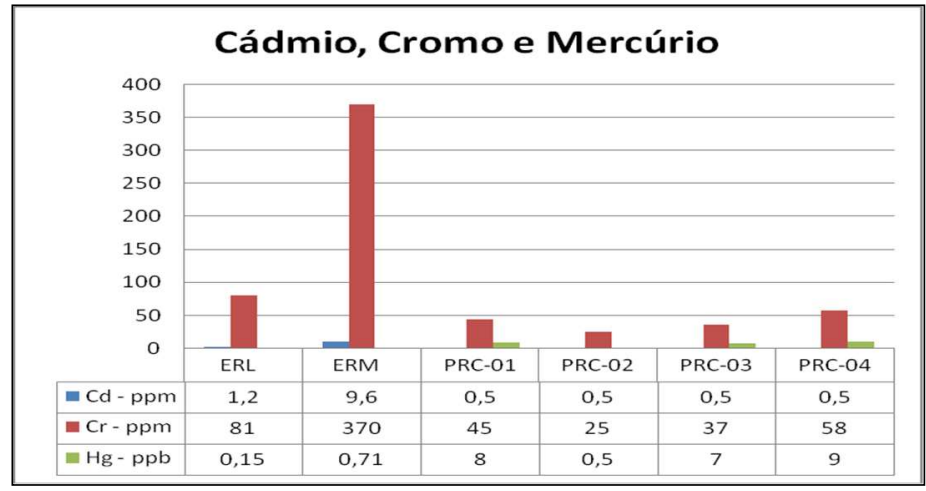

Gráfico 3: Análise Comparativa de Cd, Cre $\mathrm{Hg}$ com os parâmetros ERL e ERM.

Quando as amostras coletadas são comparadas aos parâmetros da ERL e ERM, padrão utilizado pela USEPA e outros órgãos de controle ambiental no mundo, inclusive pelo CONAMA no Brasil, chega-se 
aos seguintes resultados: para $\mathrm{Cd}, \mathrm{Cr}$ e $\mathrm{Zn}$, do rio em estudo, todas as amostras estão abaixo do nível mínimo, ou seja, não apresentam por enquanto riscos de contaminação ao meio, bem como não afetam a biota.

No caso do cádmio, todas as amostras do Rio Cotunguba apresentam índice com baixo teor, seus níveis de toxidades estão dentro dos parâmetros recomendado pela USEPA, diferenciando-se das bacias analisadas, como é o caso do Cabo (ARAÚJO, 2014) acima do mínimo, mas abaixo do limite máximo e Amazonas (SIQUEIRA et al., 2006) que apresentam patamares acima do limite máximo.

Quando analisado o elemento Cromo, boa parte dos rios do Estado aferidos encontra-se em estado de alerta, pois está muito próxima do ERM, como é o caso do Rio São Francisco, Pereira (2017) e do Cabo, conforme Araújo (2014). Não utilizando como parâmetro para comparação entre os resultados, pois se entende que as condições geoquímicas são totalmente diferentes, ainda assim vale destacar que os índices de contaminação dos sedimentos nas regiões estuarinas dos rios Capibaribe, Xavier (2011), Goiana, Lima (2011) e Botafogo, Lima (2008) também se aproximam do limite máximo recomendado. Porém, no caso dos sedimentos do Rio Cotunguba, todos os pontos de coletas estão abaixo do nível mínimo de contaminação, mas chama a atenção à variação entre os pontos 02 e 04 , que apresenta um teor com diferença de mais de $100 \%$ entre eles.

Para o elemento Hg, os PRC01, PRC03 e PRC04 do Rio Cotunguba já estão acima do limite de tolerância da ERL e em dois dos pontos de coletas, também acima do ERM. Apenas o PRC02 não apresenta índice preocupante. Quando comparado com os demais rios em análise, praticamente todos eles também apresentam índice de $\mathrm{Hg}$ acima do recomendado.

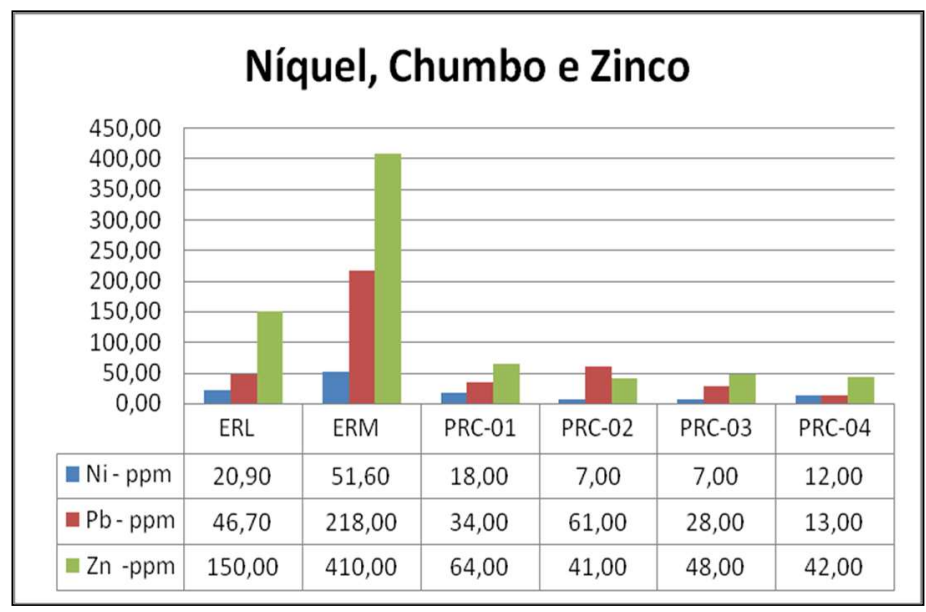

Gráfico 4: Análise Comparativa de Ni, Pb e Zn com os parâmetros ERL e ERM.

Quando analisada a questão no Níquel, todas as amostras se comportam dentro do esperado, com nenhuma delas se aproximando sequer do mínimo aceitável pelo parâmetro em estudo. Observa-se uma estabilidade entre os pontos 02 e 03 e um aumento de pouco mais de $90 \%$ no ponto 04 e $150 \%$ em relação ao ponto 01 . Ao se comparar com análises em outras bacias do estado, vai se observar que os parâmetros não estão muito diferentes, pois no Rio São Francisco os índices se comportam entre o limite mínimo e máximo tolerável, conforme Pereira (2017) e no Cabo, segundo Araújo (2014).

Já em relação ao elemento Pb, em apenas uma das amostras coletadas, o PRC02 do rio em estudo, 
apresentou um número que inspira cuidado, apesar de estar dentro da margem de tolerância do ERL, todos os outros pontos de coletas mostraram teores abaixo do parametrizado. A mesma tendência se observa nos demais rios que estão sendo usados como parâmetro para este estudo, como é o caso do Cabo, Araújo (2014), São Francisco, Pereira (2017) e Capibaribe, Paiva (2005). O mesmo pode ser observado na Bacia do Rio Amazonas, apresentando nível de toxidade entre o ERL e ERM, conforme Siqueira et al (2006).

Em relação ao $\mathrm{Zn}$, os resultados deste trabalho também apresentam números abaixo dos padrões de ERL, porém, dois rios no estado estão acima do ERL (Cabo e São Francisco), mas, nenhum dos rios analisados ultrapassam o limite máximo do ERM.

\section{Análise dos Sedimentos do Rio Cotunguba Conforme Protocolo de Thomas}

Thomas em sua obra (1987), traz à luz parâmetros importantes quanto ao processo de análise de sedimentos contaminados por metais traços, bem como medidas corretivas para o tratamento desses sedimentos. O protocolo de Thomas aponta que os sedimentos são grandes absolvidores de elementos tóxicos e que a sua dessorção na maioria das vezes é lenta, que nem sempre é capaz de ser restabelecida. Isso se dá porque, segundo ele, o impacto causado pela poluição do sedimento no ecossistema é consideravelmente mais intenso que do ar e da água, por exemplo.

Mesmo este protocolo existindo, há mais de três décadas, ele ainda é muito utilizado como referência por causa do seu rigoroso padrão ambiental, Carvalho (2014). Dentro de suas análises, o parâmetro se divide em três níveis: o não poluído, quando os sedimentos apresentam teores dentro do aceitável, o moderadamente poluído, quando apesar de estar poluído, ainda, não compromete em definitivo o status quo do rio, inclusive sendo possível seu restabelecimento e, por fim, o altamente poluído, situação que praticamente já coloca o rio em uma condição de risco total ao seu próprio ecossistema, bem como aos que deles dependem.

Tabela 4: Protocolo de Thomas: parâmetros de grau de poluição dos sedimentos conforme concentração de espécies metálicas. Comparação com os sedimentos do Rio Cotunguba.

\begin{tabular}{|c|c|c|c|c|c|c|c|}
\hline Metal & Não poluído & Moderadamente poluído & ALTAMENTE POLUÍDO & PRC-01 & PRC-02 & PRC-03 & PRC-04 \\
\hline Cd-ppm & ---- & ---- & 6 & $<0,5$ & $<0,5$ & $<0,5$ & $<0,5$ \\
\hline $\mathrm{Cr}-\mathrm{ppm}$ & $<25$ & $25-50$ & $>50$ & $45^{*}$ & 25 & 37 & $58 * *$ \\
\hline Hg- ppb & $\mathrm{SP}$ & SP & $\mathrm{SP}$ & 8 & $<0,5$ & 7 & 9 \\
\hline $\mathrm{Ni}-\mathrm{ppm}$ & $<20$ & $20-50$ & $>50$ & 18 & 7 & 7 & 12 \\
\hline Pb- ppm & $<90$ & $90-200$ & $>200$ & 34 & 61 & 28 & 13 \\
\hline Zn- ppm & $<90$ & $90-200$ & $>200$ & 64 & 41 & 48 & 42 \\
\hline
\end{tabular}

* os resultados estão acima do nível mínimo, mas, abaixo do nível máximo. ** nível acima do limite máximo aceitável para este parâmetro.

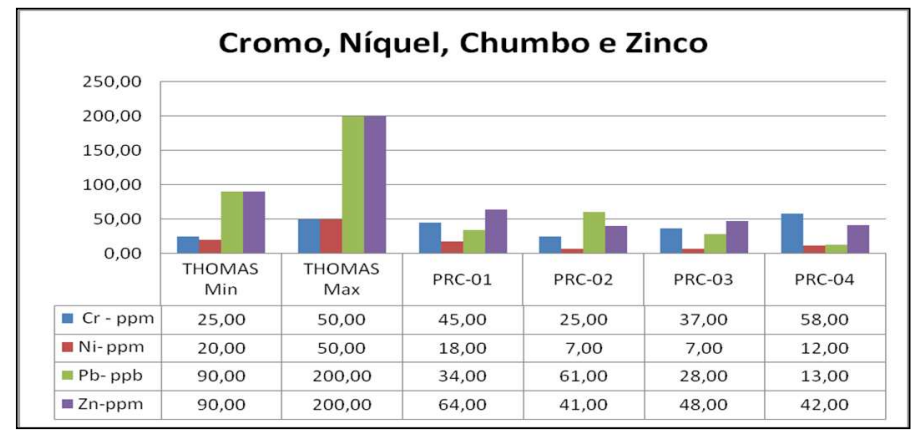

Gráfico 5: Análise Comparativa de $\mathrm{Cr}$, Ni, $\mathrm{Pb}$ e $\mathrm{Zn}$ com os parâmetros THOMAS. 
Quando analisado o resultado dos sedimentos do trabalho em questão, confrontando-os com o Protocolo de Thomas (1987), observa-se que praticamente todos os elementos, com exceção do cromo, que nas amostras 01,02 e 03 se situam dentro do nível moderadamente poluído e no 04 aparece no altamente poluído, os demais elementos analisados estão abaixo dos níveis parametrizados pelo autor. 0 que parece ser justificado pelo fato do Cotunguba não se localizar em área de grande concentração industrial, uma das principais fontes de inputs para contaminação dos sistemas fluviais, Ruppenthal (2014). Os metais traços que mais aparecem na faixa do moderadamente poluído e altamente poluído nos rios de Pernambuco são o cromo, chumbo e zinco, conforme dados do CPRH (2018). Para o Cr as Bacias do Cabo de Santo Agostinho e São Francisco são os mais críticos, com números três vezes maiores que o recomendado. Para o chumbo, todas as bacias hidrográficas de Pernambuco (Cabo, Capibaribe e São Francisco) utilizadas como parâmetro nesse estudo se comportam dentro dos padrões aceitáveis.

\section{CONCLUSÕES}

Sedimentos são fontes importantes para identificação das mais diversas formas de poluição, em especial os metais traços. Corroborando com isso, o estudo do material do Rio Cotunguba, no município de Feira Nova - PE, traz informações valiosas e em determinados pontos preocupantes no que se refere ao nível de contaminação por metais traços em seus sedimentos, resultando em sérios problemas aos seres humanos e a todo ecossistema existente no seu entorno.

As ações antrópicas advindas do avanço da urbanização e da industrialização, a ausência de políticas públicas mais efetivas e o descumprimento das leis existentes no país, como é o caso da lei dos resíduos sólidos e do lançamento de efluentes, evidenciaram, através das amostras, que foram coletadas e analisadas, que praticamente todos os pontos analisados apresentam pelo menos um elemento químico altamente poluente, acima dos parâmetros aceitáveis pelos órgãos de controle (USEPA, EC e CONAMA). A presença de metais traços como o cromo, mercúrio e o chumbo nas amostras PRC1, PRC3 e PRC4, bem acima dos níveis de tolerância e os mais diversos males causados a toda biota, resultantes do contato direto ou indireto com estes elementos, ensejam ações urgentes e efetivas no intuito de mitigar os impactos por eles causados e cessando a continuidade dos lançamentos deles nas águas do Rio Cotunguba e por conseguinte em seus sedimentos.

Apropriar-se dessas informações, mune o poder público de instrumentos que possibilitam atuar com mais objetividade e efetividade na prevenção de ações dessas naturezas. Além disso, mune também a sociedade civil (agências de controle, organizações não governamentais e imprensa), importantes atores no processo de cobrança e fiscalização das ações, tanto de seus pares, como de seus representantes.

No entanto, é importante considerar ainda que não se deva esperar apenas as ações do poder público. Um trabalho contínuo de conscientização ambiental da população que reside nos municípios que fazem parte da bacia hidrográfica do rio e que usufrui das águas da barragem, incluindo também, principalmente, a ribeirinha, precisa ser implementado urgentemente, porque parte do processo de contaminação que tem ocorrido, de forma sistemática e contínua, tem sido causado pela referida 
população, ainda que o faça sem intencionalidade.

Apesar de tantos problemas e consequências desastrosas, não se pode afirmar que a história e/ou função deste rio chegou ao seu fim, pois algumas ações mitigadoras podem ser adotadas com o objetivo de reverter o quadro e reaver a sua "saúde" e restabelecer o equilíbrio ambiental do mesmo. Para isso, basta que o poder público se posicione de forma a cumprir o seu papel. Saliente-se que os esgotos, além de serem o principal poluidor, segundo dados da COMPESA, algo em torno de $66 \%$ deles, no estado, não são tratados antes de serem lançados nos rios, número que, aqui em Feira Nova, atinge os 100\%, uma vez que não há nenhuma estação de tratamento de esgotos, não fiscaliza e coíbe que outros agentes também o façam. Isso contribui de forma direta para o definhamento do rio.

Preocupa consideravelmente também o fato de que, com toda essa ação poluidora, a água que é ofertada à população abastecida pela barragem, não seja de uma qualidade satisfatória e que atendam o que determina as legislações do CONAMA para o uso e oferta. Diante disso, um estudo dos sedimentos do rio, bem como um bom trabalho de caracterização da área, poderá contribuir consideravelmente para que os serviços prestados melhorem, influenciando diretamente na qualidade de vida das pessoas, objeto principal do poder público, bem como, reduzindo custos e processos no seu tratamento e oferta.

Por outro lado, não se pode pensar apenas na oferta da água à população e no custo que isso possa acarretar à empresa fornecedora. Mas, precisamos, como afirma Leff (2013), pensar na posteridade, tratar essa questão como uma situação micro, mas não esquecer que ela faz parte do macro e que os ecossistemas se integram, principalmente os dos limnociclos que são hoje os mais suscetíveis a processos de poluição. Sendo assim, cuidar do entorno desse rio, mapear os potenciais poluidores e verificar através de análises em laboratório a situação dos sedimentos desse rio, além de buscar junto ao poder público e à população em geral uma conscientização do cuidar, para manter e garantir que populações futuras também possam usufruir, pois esse é o real conceito de sustentabilidade.

A continuidade no processo de pesquisas no rio em pauta, aprofundando e alargando as discussões, é fundamental para o restabelecimento do seu equilíbrio. Consciente de que este trabalho é apenas um pontapé inicial e que ainda haja muito a ser estudado, anseia-se para que outros estudos surjam e que possam, com suas contribuições, apontar caminhos e medidas que visem à vida e sustentabilidade do Cotunguba.

\section{REFERÊNCIAS}

ARAUJO, P. R. M.. Teores de Referências e Geoquímica de Metais Pesado em Solo da Bacia do Cabo- PE. Dissertação (Mestrado em Ciências do Solo) - Universidade Federal Rural de Pernambuco, Recife, 2014.

ARINE, D. R.. Análise de águas de superfície e sedimentos de rios da região de Iperó, SP, por espectrometria de absorção atômica e por ativação neutrônica. São Paulo, 2000.

BRASIL. Instituto Brasileiro de Geografia e Estatística. Panorama das Cidades Brasileiras. 2017.

BRYAN, G. W.; LANGSTON, W. J.. Bioavailability, accumulation and effects of heavy metals in sediments with special reference to United Kingdom estuaries. Environmental Pollution, n.76, p.89-131, 1992.

BRAYNER, F. M. M.; SILVA H. K. P.; MACEDO S. J.. Avaliação das Concentrações de Metais Traço Nos Sedimentos do Parque dos Manguezais, Região Metropolitana do Recife (RMR), Pernambuco. 2008.

CARVALHO, J. A. R.. Comportamento Geoquímico de Sedimentação Estuarina Próximo de Embocadura Fluvial: Caso do Rio Timbó, Estado de Pernambuco. Tese (Doutorado em Geologia) - Universidade Federal de Pernambuco, Recife, 2014. 
COIMBRA, C. D.; CARVALHO, G.; PHILIPPINI, H.; SILVA, M. F. M.; NEIVA, E.. Determinação da Concentração de Metais Traço em Sedimentos do Estuário do Rio Maracaípe PE/Brasil. 2015.

FÖRSTNER, U.; WITTMANN, G. T. W.. Metal pollution in the aquatic environment. 2 ed. Berlim: Springer-Verlag, 1983.

JESUS, H. C. D.; COSTA, E. D. A.; MENDONÇA, A. S. F.; ZANDONADE, E.. Distribuição de metais traços em sedimentos do sistema estuarino da llha de Vitória - ES. Química Nova, v.27, n.3, p.1-15, 2004.

LEFF, E.. Saber Ambiental: sustentabilidade, racionalidade, complexidade, poder. 6 ed. Petrópolis: Vozes, 2013.

LIMA, E. A. M.. Avaliação da qualidade dos sedimentos e prognostico geoquímico ambiental da zona estuarina do rio Botafogo, Pernambuco. Tese (Doutorado em Geologia) Universidade Federal de Pernambuco, Recife, 2008.

MARCONI, M. A.; LAKATOS, E. M.. Técnicas de pesquisa. 5 ed. São Paulo: Atlas, 2010.

MINAYO, S.. Técnicas e Metodologia de Pesquisa. 10 ed. São Paulo, Editora LTR, 2008.

MIRANDA, J. B.. Evolução geoquímica e ambiental dos sedimentos médio-estuarinos do Rio Goiana- Pernambuco, nos três últimos séculos. Tese (Doutorado em Geologia) Universidade Federal de Pernambuco, 2016.

OMS. Organização Mundial da Saúde Relatório da Organização Mundial da Saúde sobre as Doenças Resultantes dos Metais traços, 2015.
PAIVA, A. C.. Dispersão de Chumbo em Ambientes Aquáticos da Região de Belo Jardim- PE. Dissertação (Mestrado em Engenharia Civil)- Universidade Federal de Pernambuco, Recife, 2005

PEREIRA, I. F. M.. Genotoxicidade como parâmetro de monitoramento ambiental do Rio São Francisco no Pólo de Petrolina-PE e Juazeiro-BA. Dissertação (Mestrado em Geologia) - Universidade Federal de Pernambuco, Recife, 2017.

FIDEM. Relatório de Planejamento dos Municípios de Pernambuco. 2013.

SOUZA, N. G. A.. Estudo geoquímico e geocronológico dos sedimentos de fundo do sistema estuarino Goiana-Megaó, Pernambuco. Tese (Doutorado em Geologia) - Universidade Federal de Pernambuco, Recife, 2013.

THOMAS R. L.. A Protocol for the selection of processoriented remedial options to control in situ sediment contaminants. Hidrobiology, p.247-248, 1987.

VOLPATO, S. B.; MENEZES, C. T. B.; SILVA, J. V. F.

Recuperação ambiental de ecossistemas aquáticos em regiões estuarinas: estudos aplicados para o tratamento de sedimentos contaminados pela drenagem ácida de mina na Bacia Hidrográfica do Rio Urussanga. Eng.Sanit. Ambient, v.22, n.2, p.313-316, 2017.

XAVIER, D. A.. Sedimentação recente do médio e baixo estuário do Rio Capibaribe. Tese (Doutorado em Geologia) Universidade Federal de Pernambuco, Recife, 2009. 